\title{
Salivary Biomarkers in Psychological Stress Diagnosis
}

\author{
*Patrícia Batista ${ }^{1}$ \\ Portuguese Catholic University, Porto, Portugal
}

Anabela Pereira ${ }^{2}$

Education and Psychological Department, Aveiro University, Portugal

Ana Beatriz $\mathrm{Vaz}^{3}$

Faculty of Medicine, Salamanca University, Salamanca, Spain

\begin{abstract}
:
Background: Nowadays, the search for biomarkers has attracted attention in medical and psychological sciences. The biomarkers are crucial to prevent diseases, to detect pathologies and to induce quality of life in patients. Recent studies evaluate stress biomarkers and provide information about physiological and psychological organism reactions to stressors. These biomarkers can be assessed via motoring corporal fluids (serum, plasma, urine and salivary fluid) and the proteins most used within stress salivary biomarkers are cortisol, $\alpha$-amylase, proinflammatory cytokines, and catecholamines. The aim of this paper is to review systematically the scientific literature about the evaluation of salivary biomarkers in psychological stress diagnostic.
\end{abstract}

Main Body: A systematic literature search review of Pubmed, Medline and Scopus database using the terms "salivary biomarkers" AND "psychological stress" AND "diagnostic" showed an increase in the number of studies using salivary biomarkers. It was analyzed all the existing articles (between 1997 and 2015). The inclusion criteria were: salivary biomarkers in diagnosis psychological stress, papers written in English. It was excluded the articles outside the scope of the subject, studies of animal disease models, stress methodologies and laboratory protocols, religious practices and stress; publications in languages other than English, and articles with unavailable information.

After applying the methodology, 54 scientific articles were included in the study and analyzed. The review proved that salivary cortisol and alpha-amylase biomarkers are more used to diagnosis stress diseases.

Of the 54 articles analyzed: 79\% referred to cortisol biomarker as most biomarker used, followed by salivary amylase. These two salivary biomarkers jointly accounted $27 \%$ of the articles referred.

Conclusions: This literature review is based on the contribution of salivary biomarkers to psychological stress diagnosis, understanding the diseases and their responses to treatment.

Keywords: biomarkers, salivary biomarkers, salivary cortisol, alpha-amylase, psychological stress

\section{BACKGROUND}

\section{Stress}

Stress is a complex concept, is defined as physiological and psychological reactions that prepare an organism's defense against external or internal threats (stressors) [1-3].

There are two categories of stressors: physical (systemic or reactive) and psychological (emotional or processing) [4]. Some stressors, such as prolonged mental and physical effort, different pathologies and behaviors, can induce an increase of these stress biomarkers, with pathological consequences on health [4].

Stressors are initially detected by the sensory system, and the information obtained is sent to the brain. After, the hypophysis and central nervous system activity, release corticosteroid and noradrenaline that changes the physiological state (for example, heart rate) [5]. 
The central nervous system (CNS) plays a key role in physical and psychological processes and in body's response to a stressor. Physical and psychological stress reactions are characterized by the activation of the:

a) hypothalamic-pituitary-adrenal (HPA) axis, with the secretion of glucocorticoids (cortisol) into the blood circulation;

b) autonomic nervous system (ANS) and the release of catecholamines into the blood circulation. The sympathetic component of the ANS is responsible for different effects (heart and respiratory rate, blood flow to muscles) $[2,3,6]$.

Acute stress activates a coordinated set of physiological responses (by the Sympathetic Nervous System and HPA) that prepares the body to deal with an immediate threat $[7,8]$.

Chronic stress has the capacity to increase or decrease HPA activity, and the responses depend on the stressor and the person $[2,7,9,10]$. Chronic stress has potential to cause health problems. Chronic activation of the stress-response can increase the risk of fatigue, depression, hypertension, cardiovascular diseases, ulcers, cognitive decline, cancer, immune function, atopic dermatitis, oral diseases, neurodegenerative diseases, psychological diseases [1]. Stress can alter oral homeostasis and is associated with gingivitis, periodontal diseases; development of halitosis too [11]. Stress has been associated with emotional eating behavior and symptoms of atopic dermatitis and other skin pathologies (wound healing, burns) are often aggravated by stress [12-14].

Stress is a psychosocial problem too $[15,16]$. Therefore, the responses to psychological stress are multidimensional, presenting dimensions as psychosocial and physical responses [17]. Stress may elicit a range of emotions, pathologies, behaviors, thus a better understanding of this relationship may lead to the development of behavioral interventions targeting health-promoting ways of responding emotionally to stress [8].

Over the past decade, there has been a dramatic increase in studies evaluating stress biomarkers. These biomarkers provide information about chronic and acute stressors [18]. It is crucial to monitor such biomarkers to prevent diseases, stress-related pathologies, to evaluate behavioral strategies or treatments and improve the quality of life in patients. The stress biomarkers are very important to monitor and to prevent [1-4].

Nowadays, two methods are often used to evaluate stress: a psychological test and a biomarkers test [16].

\section{Stress Salivary Biomarkers}

Biomarkers are defined as quantifiable biological indicators of a physiological process (normal, pathophysiologic, or risk of developing a pathology [19]. These molecules have the potential to improve the identification rate of individuals at risk of developing pathologies and diagnosing symptoms.

The stress biomarkers are very important to monitor and prevent stress-related pathologies and in the evaluation of behavioral strategies [1-4].

Marrelli and collaborators (2014) emphasized the significance of these specific stress-biomarkers, which represent a powerful instrument to evaluate stress levels and that may help to reduce stress diseases and other pathologies and have a preventive effect in order to improve their quality of life [4].

The biomarkers used in the assessment of mental stress includes:

- cortisol, which reflects hypothalamic-pituitary-adrenal (HPA) axis activity;

- $\alpha$-amylase, which represents the function of the autonomic nervous system (ANS);

- proinflammatory cytokines (interleukin (IL)-6, IL-1b, and tumor necrosis factor (TNF)-a), which are related to innate immunity;

- catecholamines (dopamine, norepinephrine, and epinephrine) are synthesized and released by noradrenergic neurons (biomarkers are measured in blood) $[4,7,20]$.

There are several other stress-related substances in saliva, including dehydroepiandrosterone (substance associated with the HPA axis, chromogranin A (associated with the sympathetic nerve- 
adrenal medulla system) and secretary immunoglobulin A (associated with the immune system) $[7,21]$.

These biomarkers can be assessed via monitoring corporal fluids, serum, plasma, urine and salivary fluids.

Efficient biomarkers should be sensitive, stable, easy to measure, noninvasive and without painful collection procedures for patients [19]. Therefore, special attention has been given to identifying physiological biomarkers of stress in salivary fluid. Saliva has been increasingly used as a good diagnostic or disease activity marker in many diseases (cancer, asthma, diabetes, cardiovascular diseases, ...), and in stress research [20]. This fluid can be obtained easily without incurring adverse effects. Some recent studies have used the measurement of stress hormone levels in saliva as a noninvasive method, easy to collect and without painful procedures of evaluating mental stress $[7,20$ 24]. Invasive procedures such as collection of blood, may induce mental stress and make accurate evaluation more difficult [24]. Salivary biomarkers of stress can minimize some of the potential confounding variables associated with blood sampling [3].

Over the past decade, there has been a dramatic increase in studies evaluating salivary biomarkers of stress. Salivary cortisol level was used as an endocrine marker and salivary alpha-amylase activity as a sympathetic nervous system stress marker [7,19,24]. These salivary biomarkers can provide valuable information about HPA axis and CNS activity, which are activated in response to stress [1].

\section{Cortisol}

Cortisol is a steroid hormone (also known as hydrocortisone), produced by the adrenal glands in response to the adrenocorticotropic hormone, and is the final product of the hypothalamic-pituitaryadrenal (HPA) axis $[12,14,18,25]$. So, cortisol can directly influence the central nervous system, affecting those brain's areas involved in the control of blood pressure [4].

Cortisol is historically used in research as a substantiated physiological measure of stress and anxiety, the cortisol levels reflect psychological stress. During stressful situations (acute and chronic stress), the body responds by increasing the production of cortisol, secreted by the adrenal cortex in the HPA axis $[14,25]$. Circadian rhythm, negative feedback, and stress reactions are known as factors that regulate cortisol secretion [21]. Circadian rhythm of cortisol secretion, present a typical diurnal variation increase in the early morning hours (cortisol awakening response) and decreases in the evening [7,9,21,25-27]. It is the most frequently investigated stress biomarker, assayed as a stressresponsive biomarker because cortisol is associated with many physiologic and psychobiological processes (cell death, neural development, learning and memory, sleep, metabolism, aging, immune function) [14,18]. Several studies have measured serum, urinary, and salivary cortisol [12].

Salivary cortisol is often used as a noninvasive sampling method and used as a method to evaluate stress [12,18,21]. It has been successfully used as a biological marker of HPA axis activity in epidemiological studies, increased psychological stress triggers activation of the HPA axis and related hormones $[9,18,20]$. This hormone plays an important role in maintaining homeostasis.

Some studies about stress and cortisol salivary stress marker were significantly correlated with diseases and suggested that stress might be associated with the activity of diseases as a result of physiological and behavioral mechanisms. Based on these findings, the salivary cortisol level reflects psychological stress, and it is a good index to assess chronic stress [14].

\section{Alpha-amylase}

Salivary alpha-amylase (sAA) is a human enzyme produced by the salivary glands and is regulated by the sympathetic nervous-adrenomedullary system, which controls blood noradrenaline and adrenaline levels $[5,7,12,16,21,28]$. It is one of the major proteins in saliva, it is produced by the epithelial acinar cells of the salivary glands, unlike salivary cortisol (is produced in endocrine glands and diffused into saliva) [12, 17,29]. It is a surrogate marker of CNS activity, providing evidence that sAA is responsive to stress and reflects the fast activation pattern of the CNS [12]. The activation of the autonomic nervous system has a strong influence over the salivary glands and controls the secretion of sAA [12,28]. 
There are two regulatory pathways for increasing salivary amylase activity: hormonal regulation by noradrenaline and direct innervations (stimulates the secretion of salivary amylase and elicits a quicker response than hormonal regulation) [5]. Some studies reported that physiological and psychological stress were associated with the increase in sAA activity [5,16,17,27,30,31]. It has also been reported that salivary amylase elicits a more sensitive response to psychological stress than cortisol produced in the hypothalamic- adrenocortical pathway [5]. The use of corticosteroid in some treatments can limit the cortisol levels. Cortisol as a measure of stress can be problematic and a promising alternative is sAA, a noninvasive, surrogate biologic marker of psychological stress not affected by corticosteroid use [17].

Salivary alpha-amylase can serve as a non-invasive rapid and easy measure of adrenergic activity in humans $[3,16,29]$.

Cytokine

Khalaila and collaborators (2014) studied cytokines function in stress. In their study, cytokine has potential biomarkers to predict the development of post-traumatic stress symptoms [19]. However, they reported that cortisol responses to mild psychological stress are inversely associated with proinflammatory cytokines [19].

\section{Catecholamines}

Stress responses are exerted via the hypothalamic-pituitary-adrenocortical (HPA) axis and the sympathetic nervous system, and resulting in the secretion of stress hormones, for example, cortisol and catecholamines $[12,19]$.

Levels of cortisol and catecholamines have an effect on a wide range of physiological processes throughout the body, such as the metabolism, and can cause changes in the level of secretion of various molecules (in blood or saliva) [19,32].

Cortisol and catecholamines can be assessed as biomarkers of the stress effects. However, it is difficult to measure catecholamine concentration in saliva, because it has low levels and rapid degradation. Therefore, salivary chromogranin $\mathrm{A}(\mathrm{CgA})$ is used as a substitute marker for catecholamines. $\mathrm{CgA}$ is a glycoprotein stored and secreted by the adrenal medulla and sympathetic nerves along with catecholamines. Its secretion correlates with the sympathoadrenal release of catecholamines [7]. Den and colleges conclude that chromogranin A reflects psychological stress more quickly and sensitively than cortisol [22].

Immunoglobulin

Similarly to cortisol, salivary immunoglobulin levels are known to increase in association with stress conditions [4]. Particularly, Secretory immunoglobulin A (sIgA) (dominant antibody in saliva) has also been reported to be a biomarker of stress in several studies and has been shown to be increased under mental stress conditions $[4,7,11]$.

Therefore, Masilamani and researchers (2012) have reported the response of salivary IgA in chronic work stress, and have examined the association between chronic work stress and salivary IgA levels and found an inverse relationship [10].

\section{Salivary $\mathrm{pH}$}

Salivary $\mathrm{pH}$, as a biomarker of stress or depression, might be an easy, inexpensive and noninvasive measure. However, there are few studies that could be found which the effect of stress on levels of $\mathrm{pH}$ was measured [19].

Salivary $\mathrm{pH}$ levels are found to change with the activation of the sympathetic nervous system under stress, which leads to a lowering of the rate of saliva secretion from the saliva glands in the mouth [19].

There are many others biomarkers that have been measured and studied in saliva, but with an inadequate characterization (very low concentrations or are not clinically useful) [7].

The present study is designed in order to analyze salivary biomarkers as a possible marker of psychological stress diagnosis. 


\section{METHODS}

In this review, we analyzed the role of salivary biomarkers in psychological stress diagnosis. This reflective systematic literature review, are effected by analyzed papers between 1997 and 2015. We identified scientific published papers in international journals, using a search of the databases in digital format, MedLine and PubMed, and in a second phase Scopus. The descriptors used in the research were: ["SALIVARY STRESS BIOMARKERS"] with 480 publications; ["SALIVARY BIOMARKERS" AND "PSYCHOLOGICAL STRESS"] with 230 articles, and ["SALIVARY BIOMARKERS" AND "PSYCHOLOGICAL STRESS" AND "DIAGNOSTIC"] which were obtained 112 publications. We analyzed 54 publications obtained in this review.

The inclusion and exclusion criteria from analysis were:

a) Inclusion: salivary biomarkers in diagnosis psychological stress.

b) Exclusion: outside the scope of the subjects; studies of animal disease models; methodologies, programs and stress protocols; religious practices and stress; publications in languages other than English, and articles with unavailable information.

PRISMA criteria for preferred reporting items for systematic reviews and meta-analyzes (Prisma) ${ }^{a}$ were applied. The collected information was compiled and analyzed regarding the year of publication, authors, pathologies associated with stress, salivary biomarkers.

The bibliographic references were made through the computer program EndNote bibliographic referencing.

\section{ANALYSIS OF RESULTS AND DISCUSSION}

Currently, there has been a dramatic increase in studies evaluating salivary biomarkers of stress. Salivary cortisol and alpha-amylase are the salivary stress biomarkers most used. Salivary cortisol is used as an endocrine marker and salivary alpha-amylase activity as a sympathetic nervous system stress marker [19,24]. These salivary biomarkers can provide valuable information about HPA axis and CNS activity, and are activated in response to stress [1].

In our days, for a better understanding of the systematic literature review, the analyzed studies were compiled in a summary table (Table 1). In this table there are five items: year of publication/authors, aim of study, salivary biomarkers, others biomarkers and associated diseases.

Table 1. Most relevant articles that met the inclusion criteria in this study

\begin{tabular}{|c|c|c|c|c|}
\hline Author & Aim & $\begin{array}{c}\text { Salivary } \\
\text { biomarkers }\end{array}$ & $\begin{array}{c}\text { Other } \\
\text { biomarkers }\end{array}$ & $\begin{array}{l}\text { Associate } \\
\text { diseases }\end{array}$ \\
\hline [1] & $\begin{array}{l}\text { To compare parenting responsibility, distress, anxiety, depression, } \\
\text { cortisol, alpha-amylase, and cardiovascular activity between } 19 \\
\text { mother- father dyads of children with autism spectrum disorders. }\end{array}$ & $\begin{array}{l}\text { Cortisol, } \\
\text { Alpha- } \\
\text { amylase }\end{array}$ & $\begin{array}{l}\text { Cardiovasc } \\
\text { ular activity }\end{array}$ & $\begin{array}{l}\text { Behavior, Health } \\
\text { Care, Autism }\end{array}$ \\
\hline$[20\}$ & $\begin{array}{l}\text { To investigate the relationship between systemic } \\
\text { lupus erythematosus disease activity and mental } \\
\text { stress, and the usefulness of saliva as an assessment index for stress in } \\
\text { patients with SLE. }\end{array}$ & $\begin{array}{l}\text { Cortisol, } \\
\text { Alpha- } \\
\text { amylase, IL- } \\
\text { 1b }\end{array}$ & $\begin{array}{l}\text { Anti- } \\
\text { chromatin } \\
\text { antibody }\end{array}$ & $\begin{array}{l}\text { Systemic lupus } \\
\text { erythematosus }\end{array}$ \\
\hline [33] & $\begin{array}{l}\text { To evaluate the relationship between sleep bruxism and perceived } \\
\text { stress through the estimation of stress-related biomarkers (cortisol, } \alpha \text { - } \\
\text { amylase) in saliva }\end{array}$ & $\begin{array}{l}\text { Cortisol, } \\
\text { Alpha- } \\
\text { amylase }\end{array}$ & & Sleep Bruxism \\
\hline [12] & $\begin{array}{l}\text { To assess the sensitivity of salivary cortisol and sAA in detecting stress } \\
\text { during acute burn wound care procedures and to investigate the body's } \\
\text { physiological stress reactions throughout burn re-epithelialization. }\end{array}$ & $\begin{array}{l}\text { Cortisol, } \\
\text { Alpha- } \\
\text { amylase }\end{array}$ & & Burn wound care \\
\hline [19] & To examine the levels of salivary $\mathrm{pH}$ as a possible biomarker & Salivary $\mathrm{pH}$ & - & - \\
\hline [8] & $\begin{array}{l}\text { To address both issues in male and female individuals by assessing the } \\
\text { role of anger and fear in predicting heart rate and cortisol stress } \\
\text { responses using both self-report and facial coding analysis to assess } \\
\text { emotion responses. }\end{array}$ & Cortisol & Heart rate & $\begin{array}{l}\text { Behaviors } \\
\text { (emotions) }\end{array}$ \\
\hline [4] & $\begin{array}{l}\text { To analyze the hormonal, immune and cardiovascular responses } \\
\text { induced by stress conditions in oral surgeons. }\end{array}$ & $\begin{array}{l}\text { Cortisol, } \\
\text { Immunoglo } \\
\text { bulin A, }\end{array}$ & $\begin{array}{l}\text { Heart rate, } \\
\text { Systolic } \\
\text { blood } \\
\text { pressure }\end{array}$ & Job \\
\hline [24] & To investigate the influence of chewing time on salivary stress markers & $\begin{array}{l}\text { Cortisol, } \\
\text { Alpha- } \\
\text { amylase }\end{array}$ & & $\begin{array}{l}\text { Behaviors } \\
\text { (chewing) }\end{array}$ \\
\hline
\end{tabular}


Patrícia Batista et al.

\begin{tabular}{|c|c|c|c|c|}
\hline [11] & $\begin{array}{l}\text { to evaluate the influence of stress and gender on the production of } \\
\text { volatile sulfur compounds (VSC) and salivary biomarkers. }\end{array}$ & $\begin{array}{l}\text { Cortisol } \\
\text { Alpha- } \\
\text { amilase } \\
\text { Ig }\end{array}$ & & Oral diseases \\
\hline [9] & $\begin{array}{l}\text { To evaluate cortisol response, and the mean cortisol concentration in } \\
\text { women with a current or recent experience of abuse. }\end{array}$ & Cortisol & & $\begin{array}{l}\text { Behaviors } \\
\text { (abuse) }\end{array}$ \\
\hline [14] & $\begin{array}{l}\text { To examine the salivary cortisol levels in patients with } \mathrm{AD} \text { and } \\
\text { compared them with those of healthy control subjects. }\end{array}$ & Cortisol & $\begin{array}{l}\text { TARC, } \\
\text { IgE, } \\
\text { LDH, } \\
\text { eosinophils }\end{array}$ & Atopic dermatitis \\
\hline [34] & $\begin{array}{l}\text { To investigate the effect of acute psychological stress on glucose } \\
\text { concentrations in patients with Type } 2 \text { diabetes, in the fasting state as } \\
\text { well as in the postprandial state }\end{array}$ & Cortisol & $\begin{array}{l}\text { Heart rate, } \\
\text { blood } \\
\text { pressure }\end{array}$ & Type 2 diabetes \\
\hline [26] & $\begin{array}{l}\text { 1) Assess and compare saliva cortisol concentrations in day, } \\
\text { 2) assess the relationship between industrial noise exposure and } \\
\text { salivary cortisol concentrations, } \\
\text { 3) assess the possibility of using salivary cortisol as a possible marker } \\
\text { of noise induced stress. }\end{array}$ & Cortisol & & $\begin{array}{l}\text { Job (noise } \\
\text { exposure) }\end{array}$ \\
\hline [32] & $\begin{array}{l}\text { To examine the impact of caregiving on perceived stress and two } \\
\text { biomarkers of stress, blood pressure and salivary cortisol, using } \\
\text { longitudinal data. }\end{array}$ & Cortisol & & $\begin{array}{l}\text { Behaviors } \\
\text { (Health Care) }\end{array}$ \\
\hline [16] & $\begin{array}{l}\text { To verify whether salivary aamylase enzyme activity (Amy) is useful } \\
\text { as a biomarker of stress in pilots working in a stressful environment. }\end{array}$ & $\begin{array}{l}\text { Alpha- } \\
\text { amilase }\end{array}$ & & Job \\
\hline$[21]$ & $\begin{array}{l}\text { To clarify the day-to-day variations of salivary cortisol to discuss the } \\
\text { appropriate timing for collecting saliva in a day for stress evaluation. }\end{array}$ & Cortisol & & \\
\hline
\end{tabular}

- Articles about children and/or pregnancy

We analyzed fifty-four articles which met the inclusion criteria.

The literature review revealed many studies about salivary biomarkers. We analyzed only the studies about "salivary biomarkers AND psychological stress AND diagnostic".

Stress is a common disease in our society, it has been previously associated with clinical manifestations of cardiovascular disease, neurodegenerative diseases, mental diseases, oral diseases, infertility, cancer, pregnancy, jobs and behaviors. Understood stress is currently being explored as a potential target for diagnosis and therapeutic interventions.

The biomarker patterns may provide clinical useful information by enabling the differential diagnosis, staging, and prognosis of diseases as well as comprehension of diseases and their responses to treatment.

Stress can be measured in vivo in multiple sample types including cells, tissues, urine, blood, saliva, and others.

Several investigations have demonstrated that saliva offers an advantageous alternative to blood because its collection is noninvasive, low in cost, and safe for both the donor.

Salivary biomarkers offer a novel approach in diagnosis and treatment to stress diseases.

The salivary cortisol and salivary enzyme alpha-amylase are established as non-invasive markers of psychological and physiological stress. The review proved that these biomarkers are more used to stress diseases diagnosis, but others measures are important, for example, heart rate to analyze the physiological state, and to evaluate stress response [5].

Some studies have focused on the one salivary biomarkers, such as, cortisol or alpha-amylaze. Other studies have focused on the evaluation of two proteins during stress responses or physiological measurements.

The literature review indicated that the chronic stress is associated with the activation of the hypothalamic-pituitary-adrenal (HPA) axis (measured by salivary cortisol), as well as with the depression of immune function (measured by salivary IgA and lysozyme). The cortisol level reflects psychological stress.

Acute stress is associated with the activation of the sympatho-adreno-medullary system, which is reflected by salivary a-amylase and chromogranin A. 
These studies demonstrated that it is crucial to monitor such biomarkers to prevent diseases typically induced by prolonged and repetitive stress states.

In this review, we summarize critical knowledge of different salivary stress biomarker. However, further research and validation studies are needed for less characterized biomarkers before they can be used in daily practice.

\section{Summary of methodological limitations}

Numerous articles have been developed in the field of salivary stress biomarkers, and research was more restricted.

We found limitations in the analyzed articles: small sample sizes; different collected protocols; different times to collected samples; variability in results; few longitudinal studies.

\section{Implications for practice}

Nowadays, psychological stress is a matter of great importance to all age groups, and may lead to mental disorders and various diseases. An objective and quantitative method for measuring salivary stress-related substances is highly desired. Saliva collection is easy, stress free and noninvasive.

This literature review, suggest the future potential for monitoring stress biomarkers within minutes from a trace of saliva and can contribute to disease prevention and overall good health.

\section{CONClusion}

Over the past decade, there has been a strong increase in studies evaluating salivary biomarkers of stress. However, the scientific research for biomarkers of psychological symptoms is needed to improve quality of life.

In this review, some studies about stress and salivary stress biomarkers were significantly correlated with diseases (periodontal, cancer,...) and it is suggested that stress might be associated with the activity of diseases as a result of physiological and behavioral mechanisms. Based on these findings, the salivary cortisol and alpha-amylase reflects psychological stress and are considered good salivary stress biomarkers.

To the best of our knowledge, it is needed more investigation about this subject, to diagnose psychological stress and associate treatments.

\section{ABBreviations}

CNS: central nervous system; HPA: hypothalamic-pituitary-adrenal; ANS: autonomic nervous system; IL: interleukin; TNF: tumor necrosis factor; sAA: salivary alpha-amylase; CgA: chromogranin A; sIgA: secretory immunoglobulin A.

\section{REFERENCES}

[1] Foody C, James JE, Leader G. Parenting stress, salivary biomarkers, and ambulatory blood pressure: a comparison between mothers and fathers of children with autism spectrum disorders. J Autism Dev Disord. 2015; 45: 1084-1095.

[2] Skoluda N, Strahler J, Schlotz W, Niederberger L, Marques S, Fischer S, Nater UM. Intraindividual psychological and physiological responses to acute laboratory stressors of different intensity. Psychoneuroendocrinology. 2015; 51: 227-236.

[3] Vanaelst B, Michels N, Clays E, Herrmann D, Huybrechts I, Sioen I, De Henauw S. The association between childhood stress and body composition, and the role of stress-related lifestyle factors-cross-sectional findings from the baseline ChiBSD survey. Int J Behav Med. 2014; 21: 292-301.

[4] Marrelli M, Gentile S, Palmieri F, Paduano F, Tatullo M. Correlation between Surgeon's experience, surgery complexity and the alteration of stress related physiological parameters. PLoS One. 2014;9:e112444.

[5] Matsuura T, Takimura R, Yamaguchi M, Ichinose M. Estimation of restraint stress in rats using salivary amylase activity. J Physiol Sci. 2012;62:421-427. 
[6] Santos MJ, Bernabé DG, Nakamune AC, Perri SH, de Aguiar SM, de Oliveira SH. Salivary alpha amylase and cortisol levels in children with global developmental delay and their relation with the expectation of dental care and behavior during the intervention. Res Dev Disabil. 2012; 33: 499-505.

[7] Koh DS-Q., Koh GC-H. The use of salivary biomarkers in occupational and environmental medicine. Occup Environ Med. 2007; 64: 202-210.

[8] Lupis SB, Lerman M, Wolf JM. Anger responses to psychosocial stress predict heart rate and cortisol stress responses in men but not women. Psychoneuro endocrinology. 2014; 49: 84-95.

[9] Lokhmatkina NV, Feder G, Blake S, Morris R, Powers V, Lightman S. Longitudinal measurement of cortisol in association with mental health and experience of domestic violence and abuse: study protocol. BMC Psychiatry. 2013;13:188.

[10] Masilamani R, Darus A, Ting AS, Ali R, Mahmud AB, David K. Salivary biomarkers of stress among teachers in an urban setting. Asia Pac J Public Health. 2012; 24: 278-287.

[11] Lima PO, Calil CM, Marcondes FK. Influence of gender and stress on the volatile sulfur compounds and stress biomarkers production. Oral Dis. 2013; 19: 366-373.

[12] Brown NJ, Kimble RM, Rodger S, Ware RS, Mc Whinney BC, Ungerer JP, Cuttle L. Biological markers of stress in pediatric acute burn injury. Burns. 2014; 40: 887-895.

[13] Michels N, Sioen I, Braet C, Huybrechts I, Vanaelst B, Wolters M, De Henauw S. Relation between salivary cortisol as stress biomarker and dietary pattern in children. Psychoneuroendocrinology. 2013; 38:1512-1520.

[14] Mizawa M, Yamaguchi M, Ueda C, Makino T, Shimizu T. Stress evaluation in adult patients with atopic dermatitis using salivary cortisol. Biomed Res Int. 2013:138027.

[15] Gurman GM, Klein M, Weksler N. Professional stress in anesthesiology: a review. J Clin Monit Comput. 2012;26:329-335.

[16] Iizuka N, Awano S, Ansai T. Salivary alpha-amylase activity and stress in Japan air self-defense force cargo pilots involved in Iraq reconstruction. Am J Hum Biol. 2012;24:468-472.

[17] Ameringer S, Munro C, Elswick RK. Assessing agreement between salivary alpha amylase levels collected by passive drool and eluted filter paper in adolescents with cancer. Oncol Nurs Forum. 2012; 39:E317-323.

[18] Shirtcliff EA, Buck RL, Laughlin MJ, Hart T, Cole CR, Slowey PD. Salivary cortisol results obtainable within minutes of sample collection correspond with traditional immunoassays. Clin Ther. 2015;37:505-514.

[19] Khalaila R, Cohen M, Zidan J. Is salivary $\mathrm{pH}$ a marker of depression among older spousal caregivers for cancer patients? Behav Med. 2014;40:71-80.

[20] Jung JY, Nam JY, Kim HA, Suh CH. Elevated Salivary Alpha-Amylase Level, Association Between Depression and Disease Activity, and Stress as a Predictor of Disease Flare in Systemic Lupus Erythematosus: A Prospective Case-Control Study. Medicine (Baltimore). 2015;94:e1 184.

[21] Matsuda S, Yamaguchi T, Okada K, Gotouda A, Mikami S. Day-to-day variations in salivary cortisol measurements. J Prosthodont Res. 2012;56:37-41.

[22] Den R, Toda M, Ohira M, Morimoto K. Levels of awakening salivary CgA in response to stress in healthy subjects. Environ Health Prev Med. 2011;16:155-157.

[23] Obayashi K. Salivary mental stress proteins. Clin Chim Acta. 2013;425:196-201.

[24] Tasaka A, Takeuchi K, Sasaki H, Yoshii T, Soeda R, Ueda T, Sakurai K. Influence of chewing time on salivary stress markers. J Prosthodont Res. 2014;58:48-54.

[25] Kenwright K, Liddell PW, Bloom L, Zucker-Levin A, Nolen AH, Faulkner LW, Batorski RE. Salivary cortisol levels in students challenged with a testing stressor. Clin Lab Sci. 2011;24:221226.

[26] Fouladi DB, Nassiri P, Monazzam EM, Farahani S, Hassanzadeh G, Hoseini M. Industrial noise exposure and salivary cortisol in blue collar industrial workers. Noise Health. 2012;14:184-189. 
[27] Wetherell MA, Lovell B, Smith MA. The effects of an anticipated challenge on diurnal cortisol secretion. Stress. 2015;18:42-48.

[28] Campos MJ, Raposo NR, Ferreira AP, Vitral RW. Salivary alpha-amylase activity: a possible indicator of pain-induced stress in orthodontic patients. Pain Med. 2011; 12:1162-1166.

[29] Guglielminotti J, Dehoux M, Mentré F, Bedairia E, Montravers P, Desmonts JM, Longrois D. Assessment of salivary amylase as a stress biomarker in pregnant patients. Int J Obstet Anesth. 2012;21:35-39.

[30] Nater UM, La Marca R, Florin L, Moses A, Langhans W, Koller MM, Ehlert U. Stress-induced changes in human salivary alpha-amylase activity - associations with adrenergic activity. Psychoneuroendocrinology. 2006;31:49-58.

[31] Nierop A, Wirtz PH, Bratsikas A, Zimmermann R, Ehlert U. Stress-buffering effects of psychosocial resources on physiological and psychological stress response in pregnant women. Biol Psychol. 2008;78:261-268.

[32] Ice GH, Sadruddin AF, Vagedes A, Yogo J, Juma E. Stress associated with caregiving: an examination of the stress process model among Kenyan Luo elders. Soc Sci Med. 2012;74:20202027.

[33] Karakoulaki S, Tortopidis D, Andreadis D, Koidis P. Relationship Between Sleep Bruxism and Stress Determined by Saliva Biomarkers. Int J Prosthodont. 2015;28:467-474.

[34] Faulenbach M, Uthoff H, Schwegler K, Spinas GA, Schmid C, Wiesli P. Effect of psychological stress on glucose control in patients with Type 2 diabetes. Diabet Med. 2012;29:128-131.

[35] Arora S, Aggarwal R, Moran A, Sirimanna P, Crochet P, Darzi A, Sevdalis N. Mental practice: effective stress management training for novice surgeons. J Am Coll Surg. 2011;212:225-233.

[36] Eller NH, Kristiansen J, Hansen AM. Long-term effects of psychosocial factors of home and work on biomarkers of stress. Int J Psychophysiol. 2011;79:195-202.

[37] Juster RP, Sindi S, Marin MF, Perna A, Hashemi A, Pruessner JC, Lupie SJ. A clinical allostatic load index is associated with burnout symptoms and hypocortisolemic profiles in healthy workers. Psychoneuroendocrinology. 2011;36:797-805.

[38] Kang Y. Psychological stress-induced changes in salivary alpha-amylase and adrenergic activity. Nurs Health Sci. 2010;12:477-484.

[39] Louis GM, Lum KJ, Sundaram R, Chen Z, Kim S, Lynch CD, Pyper C. Stress reduces conception probabilities across the fertile window: evidence in support of relaxation. Fertil Steril. 2011;95:2184-2189.

[40] Mundy-Bosse BL, Thornton LM, Yang HC, Andersen BL, Carson WE. Psychological stress is associated with altered levels of myeloid-derived suppressor cells in breast cancer patients. Cell Immunol. 2011;270:80-87.

[41] Pani SC, Al Askar AM, Al Mohrij SI, Al Ohali TA. Evaluation of stress in final-year Saudi dental students using salivary cortisol as a biomarker. J Dent Educ. 2011;75:377-384.

[42] Bakvis P, Spinhoven P, Giltay EJ, Kuyk J, Edelbroek PM, Zitman FG, Roelofs K. Basal hypercortisolism and trauma in patients with psychogenic nonepileptic seizures. Epilepsia. 2010;51:752-759.

[43] Marques AH, Silverman M N, Sternberg EM. Evaluation of stress systems by applying noninvasive methodologies: measurements of neuroimmune biomarkers in the sweat, heart rate variability and salivary cortisol. Neuroimmunomodulation. 2010;17:205-208.

[44] Noto Y, Kudo M, Hirota K. Back massage therapy promotes psychological relaxation and an increase in salivary chromogranin A release. J Anesth. 2010;24:955-958.

[45] Hong RH, Yang YJ, Kim SY, Lee WY, Hong YP. Determination of appropriate sampling time for job stress assessment: the salivary chromogranin A and cortisol in adult females. J Prev Med Public Health. 2009; 42: 231-236.

[46] Lang EV, Berbaum KS, Lutgendorf SK. Large-core breast biopsy: abnormal salivary cortisol profiles associated with uncertainty of diagnosis. Radiology. 2009;250:631-637. 
[47] Kukolja J, Thiel CM, Wolf OT, Fink GR. Increased cortisol levels in cognitively challenging situations are beneficial in young but not older subjects. Psychopharmacology (Berl). 2008;201:293-304.

[48] Lonne-Rahm SB, Rickberg H, El-Nour H, Mårin P, Azmitia EC, Nordlind K. Neuroimmune mechanisms in patients with atopic dermatitis during chronic stress. J Eur Acad Dermatol Venereol. 2008;22:11-18.

[49] Laures-Gore J, Heim CM, Hsu YS. Assessing cortisol reactivity to a linguistic task as a marker of stress in individuals with left-hemisphere stroke and aphasia. J Speech Lang Hear Res. 2007;50:493-507.

[50] Tahara Y, Sakurai K, Ando T. Influence of chewing and clenching on salivary cortisol levels as an indicator of stress. J Prosthodont. 2007;16:129-135.

[51] Kanamaru Y, Kikukawa A, Shimamura K. Salivary chromogranin-A as a marker of psychological stress during a cognitive test battery in humans. Stress. 2006;9:127-131.

[52] Miyakawa M, Matsui T, Kishikawa H, Murayama R, Uchiyama I, Itoh T, Yoshida T. Salivary chromogranin A as a measure of stress response to noise. Noise Health. 2006;8:108-113.

[53] van Stegeren A, Rohleder N, Everaerd W, Wolf OT. Salivary alpha amylase as marker for adrenergic activity during stress: effect of beta blockade. Psychoneuroendocrinology. 2006;31:137-141.

[54] Ehlert U, Nater UM, Böhmelt A. High and low unstimulated salivary cortisol levels correspond to different symptoms of functional gastrointestinal disorders. J Psychosom Res. 2005;59:7-10.

[55] Noto Y, Sato T, Kudo M, Kurata K, Hirota K. The relationship between salivary biomarkers and state-trait anxiety inventory score under mental arithmetic stress: a pilot study. Anesth Analg. 2005;101:1873-1876.

[56] Ahmed N, de la Torre B, Wahlgren NG. Salivary cortisol, a biological marker of stress, is positively associated with 24-hour systolic blood pressure in patients with acute ischaemic stroke. Cerebrovasc Dis. 2004;18:206-213.

[57] De Vente W, Olff M, Van Amsterdam JG, Kamphuis JH, Emmelkamp PM. Physiological differences between burnout patients and healthy controls: blood pressure, heart rate, and cortisol responses. Occup Environ Med. 2003;60 Suppl 1:i54-61.

[58] Spicer J, Werner E, Zhao Y, Choi CW, Lopez-Pintado S, Feng T, Monk C. Ambulatory assessments of psychological and peripheral stress-markers predict birth outcomes in teen pregnancy. J Psychosom Res. 2013;75:305-313.

[59] Furlan NF, Gavião MB, Barbosa TS., Nicolau J, Castelo PM. Salivary cortisol, alpha-amylase and heart rate variation in response to dental treatment in children. J Clin Pediatr Dent. 2012;37:83-87.

[60] Kaess M, Hille M, Parzer P, Maser-Gluth C, Resch F, Brunner R. Alterations in the neuroendocrinological stress response to acute psychosocial stress in adolescents engaging in nonsuicidal self-injury. Psychoneuroendocrinology. 2012;37:157-161.

[61] Lee T, Shimizu T, Iijima M, Obinata K, Yamashiro Y, Nagasawa S. Evaluation of psychosomatic stress in children by measuring salivary chromogranin A. Acta Paediatr. 2006;95:935-939. 